\title{
The Diversity of Educational and Developmental Psychology
}

The endorsed area of Educational and Developmental Psychology is a division of psychology in Australia that continues to transcend many specialisms in the field. Practitioners in this important area of practice, work in diverse fields such as health, disability, schools and geropsychology, to name but a few. The College is fortunate to cater for such an eclectic group of practitioners with a broad base of psychological practice.

This issue of the journal reflects this diversity with a range of high-quality articles that offer an array of material for practice and research in educational and developmental psychology. The first three articles have a direct connection to school psychology, although some findings will be relevant outside this domain. In the first article, Waters and Stokes report their research into the use of emotion and action gratitude for school leaders through the positive education paradigm. In the second article, Doonan and colleagues bring to the fore the issue of school education for students with cancer. This study highlights a very serious issue in regional Australia, with low levels of additional funding being available to students, as well as the necessity for a particular type of support to help these students continue to learn effectively. Leana-Tascilar reports extensive research in the domain of gifted education in Turkey, which is potentially generalisable across different countries. At certain school stages the results indicate that extrinsic and intrinsic motivation can predict academic achievement.

Allison and Campbell report original findings from their Australian study of how childhood sibling relationships can be affected by disability. A highly valuable finding in this qualitative study was that mothers reported less warmth and closeness in siblings where disability was a factor. In the final article in this issue, Grigg and Manderson discuss the creation of a scale that considers issues such as racism and ethocentricity in the Australian population. This article discusses its creation using a wide sample of school students, adolescents and adults. The results seem to indicate the effectiveness of community-based programs to reduce racist attitudes among the targeted population. 